\title{
HEAT AND MASS TRANSFER IN THE UPPER MANTLE AND THE DEEP CRUST: PETROLOGICAL INDICATORS AND MATHEMATICAL MODELING
}

\author{
A. G. Vladimirov1, 2, 3, N. N. Kruk , O. P. Polyansky1, 2, A. V. Travin1, 2, 3 \\ ${ }^{1}$ V.S. Sobolev Institute of Geology and Mineralogy, Siberian Branch of RAS, Novosibirsk, Russia \\ ${ }^{2}$ Novosibirsk State University, Novosibirsk, Russia \\ ${ }^{3}$ Tomsk State University, Tomsk, Russia
}

\section{ТЕПЛОМАССОПЕРЕНОС В ВЕРХНЕЙ МАНТИИ И ЗЕМНОЙ КОРЕ: ПЕТРОЛОГИЧЕСКИЕ ИНДИКАТОРЫ И МАТЕМАТИЧЕСКОЕ МОДЕЛИРОВАНИЕ}
А. Г. Владимиров ${ }^{1,2,3}$, Н. Н. Крук ${ }^{1}$, О. П. Полянский ${ }^{1,2}$, А. В. Травин ${ }^{1,2,3}$
${ }^{1}$ Институт геологии и минералогии им. В.С. Соболева СО РАН, Новосибирск, Россия
${ }^{2}$ Новосибирский национальный исследовательский государственный университет, Новосибирск, Россия
3 Томский государственный университет, Томск, Россия 
Глобальная геодинамика и термическая история Земли (фанерозой) определяются тепловой конвекцией в ее мантии [Dobretsov, 1993, 1995; Dobretsov et al., 2001], плюмами нижнемантийного генезиса [Morgan, 1971; Norton, 2000; Anderson, 2005; Puchkov, 2007] и астеносферными диапирами, возникающими на границе океанических и континентальных литосферных плит [Davies, Blankenbyrg, 1995; Khain et al., 1996; Tychkov, Vladimirov, 1997; Van Keken, 1997; Van Keken, Balleutine, 1999; Zhong et al., 2000; Zhong, 2006; Yochida, Santosh, 2011; Martynov et al., 2016; Khanshuk et al., 2019].

В настоящее время можно считать доказанным, что долгоживущие мантийные плюмы представляют собой обычные восходящие потоки общемантийной тепловой конвекции, которые при высокой интенсивности принимают особую грибовидную форму [Ricard, 2007; Bercovici, 2007; Trubitsyn, 2012; Trubitsyn, Evseev, 2014, 2018; Trubitsyn et al., 2015]. Химические примеси (эклогитовый компонент) являются добавкой базитового состава, понижающей температуру плавления перидотитов, а значит, будут инициировать плюмы [Dannberg, Sobolev, 2015].

Плюм-тектоника являлась эффективным механизмом теплоотдачи планеты Земля от ее зарождения и последующей термической истории остывания в архее - раннем протерозое. Кардинальная перестройка произошла на границе фанерозоя, когда был реализован механизм плейт-тектоники с двухслойной верхнемантийной конвекцией, субдукцией, надсубдукционным и коллизионным орогенезом (см. обзоры: [Dobretsov et al., 2001; Travin, 2016; Khanchuk et al., 2019]. Решающим механизмом теплоотдачи Земли явился астеносферный диапиризм, который стал отвечать за тепломассоперенос и не позволил разрушить нашу планету. Это означает, что появились новые механизмы разгрузки тепла, в первую очередь на плотностных физико-химических границах в верхней - нижней мантии, на границе Мохо и на внутрикоровых плотностных и реологических границах. На первое место вышли пограничные слои, когда горячие нижнемантийные струи вскрывают их и приводят в циркуляриционное движение все вещество верхнемантийных конвективных ячеек [Khain, Lobkovsky, 1990; Dobretsov et al., 2001; Lobkovsky et al., 2004; Schubert et al., 2004; Kuskov et al., 2014; Trubitsyn et al., 2015]. Эти численные модели основываются на геолого-геофизических данных о структуре и температурных градиентах в разрезе «верхняя мантия - земная кора», однако в них не учитываются физико-механические особенности тепломассопереноса на границах раздела сред.

Наиболее принципиальным является граница «верхняя мантия - нижняя кора», для которой уже сейчас разработаны прямые петрологические инди- каторы, позволяющие объяснить температурные градиенты в литосфере и механизмы взаимодействия мантийных и коровых расплавов (см. спецвыпуск журнала Geodynamics \& Tectonophysics [Vladimirov et al., 2017]). Этот подход позволил существенно продвинуться в понимании строения зоны перехода «нижняя кора - верхняя мантия», которая согласно [O’Reilly, Griffin, 2013] представляет собой не сейсмически резкую, а переходную зону мощностью около 10 км. Эта переходная зона, вероятно, состоит из смеси гранулитов/мантийных перидотитов ( \pm пироксениты), интрудированных базитовыми расплавами. Важно отметить, что слои или тела базитовых интрузий характерны для корово-мантийной границы под осадочными бассейнами, что фиксируется сейсмическими методами в разных регионах мира [Vladimirov et al., 2008; Bryan, Ernst, 2008; Thybo, Artemieva, 2013]. Из этих данных следует, что взаимодействие базитовых магм и корового материала будет неизбежно проявляться в составе комбинированных габбро-гранитных интрузивных серий, внутригранитных и постгранитных минглинг-даек.

Академик Ю.А. Кузнецов и профессор Э.П. Изох предложили модель контрастных габбро-гранитных интрузивных серий - петрологических индикаторов корово-мантийного взаимодействия [Kuznetsov, Izokh, 1969]. Формационный подход, позволяющий включить в системный анализ магматические тела, а не их фрагменты в виде образцов (осколков), отобранных на том или ином геологическом обнажении, оказался наиболее эффективным. Этот подход получил подтверждение при изучении Алтае-Саянской складчатой области [Shokal'skii et al., 2000; Turkina, 2002; Rudnev, 2010; Vladimirov et al., 2013] и сейчас является ключевым инструментом при составлении разномасштабных геологических карт Российской Федерации [Shokal'skii et al., 2000].

Идея о наличии каскада габбро-гранитных магматических камер была предложена при изучении Сангиленского блока Юго-Восточной Тувы [Egorova et al., 2006] и подтверждена независимым методом численного моделирования [Polyansky et al., 2019]. Остается открытым вопрос о степени контаминации базит-монцодиоритовых магм коровым веществом в процессе вертикального подъема по системе проницаемых каналов. Для габбро-монцодиоритовых массивов Западного Сангилена (Юго-Восточная Тува) установлена низкая степень контаминации корового материала [Shelepaev et al., 2018]. Наличие комбинированных даек в пределах ЗападноСангиленского блока Юго-Восточной Тувы является индикатором механического и химического взаимодействия мантийных и коровых расплавов [Vladimirov V.G. et al., 2019].

Анализ опубликованных статей в настоящем спецвыпуске журнала Geodynamics \& Tectonophysics 
[Ashchepkov et al., 2019; Vladimirov A.G. et al., 2019; Vladimirov V.G. et al., 2019; Kirdyashkin et al., 2019; Murzintsev et al., 2019; Osipova et al., 2019; Polyansky et al., 2019; Udoratina et al., 2019] позволил наметить главные направления будущих исследований, которые были обсуждены в рамках «круглого стола» на четвертой международной научной конференции «Корреляция алтаид и уралид: магматизм, метаморфизм, стратиграфия, геохронология, геодинамика и металлогения» (г. Новосибирск, ИГМ ИНГГ СО РАН, 2018 г.). Эти доклады можно условно отнести к трем группам: 1) тепломассоперенос в верхней мантии и структура мантийной литосферы; 2) петрологические индикаторы корово-мантийного взаимодействия, механизмы внедрения и сосуществования контрастных по составу магматических расплавов (базиты - граниты); 3) реконструкция термических историй остывания гранитоидных батолитов и рудно-магматических систем на разноглубинных уровнях земной коры.

Первый раздел включает статью, в которой приведена петрологическая и аналитическая сводка, полученная в результате изучения глубинных включений из кимберлитовых трубок взрыва на Сибирской платформе [Ashchepkov et al., 2019]. Благодаря присутствию алмазов в мантийных включениях (ксенолитах/автолитах), кимберлитовые трубки взрыва в настоящее время активно изучаются на всех континентах. Как следствие, они являются наиболее информативным источником, позволяющим реконструировать структуру, химический состав и Р-Т-параметры мантийной литосферы. С учетом прецизионных определений возраста $(\mathrm{U} / \mathrm{Pb}, \mathrm{Sm} / \mathrm{Nd})$ для мантийной литосферы, подстилающей Сибирскую платформу, выполнены первые палеореконструкции для девонского времени, что является принципиально важным для геодинамики Северной Евразии, включая Центрально-Азиатский складчатый пояс.

В статье [Kirdyashkin et al., 2019] приведен авторский обзор многолетних исследований, посвященных численному моделированию динамики формирования алмазоносных кимберлитовых трубок. Эта статья является важной не только в плане практических разработок, но и в фундаментальном смысле, поскольку позволяет обосновать принципиальную возможность выноса верхнемантийных включений на поверхность Земли.

Второй раздел представлен статьей, в которой приведены новые данные о глубинных базитовых включениях в гранитоидах и их индикаторной значимости для понимания генезиса корово-мантийных расплавов [Udoratina et al., 2019]. Принципиально важной является разработка минералогических индикаторов петрогенезиса [Osipova et al., 2019]. Это направление в изучении гранитоидных интрузив- ных массивов является новым подходом, способным выявить и доказать на минеральном уровне присутствие мантийного вещества в гранитоидных системах. Этот раздел завершается статьей О.П. Полянского с соавторами, в которой приведены численные расчеты физико-механического взаимодействия контрастных по составу базитовых и кремнекислых расплавов [Polyansky et al., 2019], а также статьей В.Г. Владимирова с соавторами, где детально рассмотрены критерии диагностики минглинг-даек и предложена новая петрологическая модель диспергирования и сдвиговой дилатации, способная объяснить проблему пространства на границе нижняя кора - верхняя мантия [Vladimirov V.G. et al., 2019].

Третий раздел содержит две статьи, в которых предложен новый термохронологический подход к изучению гранитоидных батолитов и рудномагматических систем [Vladimirov A.G. et al., 2019; Murzintsev et al., 2019]. Разработанный авторами математический алгоритм позволяет перейти к количественной оценке термической истории остывания крупных сегментов земной коры (террейнов), используя гранитоидные батолиты и редкометалльно-гранитные месторождения как петрологические индикаторы корово-мантийного взаимодействия.

Данные статьи отражают современные подходы к анализу минглинг-процессов и первую попытку эмпирического и модельного анализа температурных градиентов в верхней мантии и земной коре.

\section{БЛАГОДАРНОСТИ}

Представленный спецвыпуск журнала Geodynamics \& Tectonophysics посвящается памяти д.г.-м.н. Никиты Викторовича Суркова - ведущего научного сотрудника ИГМ СО РАН, г. Новосибирск. Рукопись статьи H.B. Суркова (Surkov N.V., Banushkina S.V. Melting of quartz-normative compounds with the participation of $\alpha$-diopside in connection with the Genesis of granite magmas) осталась незавершенной, однако высказанные идеи позволят в будущем реконструировать геодинамические условия формирования гранитов-рапакиви и приблизиться к пониманию реальных механизмов корово-мантийного взаимодействия. Первые шаги в этом направлении уже сделаны и опубликованы в статье [Kirdyashkin et al., 2019].

Спецвыпуск подготовлен по государственному заданию ИГМ СО РАН при финансовой поддержке Министерства науки и высшего образования Российской Федерации: проект № 5.1688.2017/ПЧ (численное моделирование), проект № 14.Y26.31.0012 (формирование компьютерной графики и построение петрологических моделей PMC), а также Россий- 
ского фонда фундаментальных исследований: проект № 16-05-00128a $\left({ }^{40} \mathrm{Ar} /{ }^{39} \mathrm{Ar}\right.$ изотопные исследования пород и руд Калгутинской РМС и гранитов Ново-Ахмировского штока), проект № 17-05-00936а (интерпретация данных геохронологических исследований, термохронологический анализ), проект № 17-05-00848 (физико-механическое численное моделирование магматических систем).

\section{ЛИТЕРАTУРA / REFERENCES}

Anderson D.L., 2005. Large igneous provinces, delamination, and fertile mantle. Elements 1 (5), 271-275. https:// doi.org/10.2113/gselements.1.5.271.

Ashchepkov I.V., Ivanov A.S., Kostrovitsky S.I., Vavilov M.A., Babushkina S.A., Vladykin N.V., Tychkov N.S., Medvedev N.S., 2019. Mantle terranes of the Siberian craton: their interaction with plume melts based on thermobarometry and geochemistry of mantle xenocrysts. Geodynamics \& Tectonophysics 10 (2), 197-245 (in Russian) [Ащепков И.В., Иванов А.С., Костровицкий С.И., Вавилов М.А., Бабушкина С.А., Владыкин Н.В., Тычков Н.С., Медведев Н.С., 2019. Мантийные террейны Сибирского кратона: их взаимодействие с плюмовыми расплавами на основании термобарометрии и геохимии мантийных ксенокристов // Геодинамика и тектонофизика. 2019. Т. 10. № 2. C. 197-245]. https://doi.org/10.5800/GT-2019-10-2-0412.

Bercovici D., 2007. Mantle dynamics past, present, and future: an introduction and overview. In: D. Bercovici (Ed.), Mantle dynamics. Treatise on Geophysics, vol. 7, p. 1-30.

Bryan S.E., Ernst R.E., 2008. Revised definition of large igneous provinces (LIPs). Earth-Science Reviews 86 (1-4), 175-202. https://doi.org/10.1016/j.earscirev.2007.08.008.

Dannberg J., Sobolev S.V., 2015. Low-buoyancy thermochemical plumes resolve controversy of classical mantle plume concept. Nature Communications 6, 6960. https://doi.org/10.1038/ncomms7960.

Davies J.H., von Blanckenburg F., 1995. Slab breakoff: a model of lithosphere detachment and its test in the magmatism and deformation of collisional orogens. Earth and Planetary Science Letters 129 (1-4), 85-102. https://doi.org/ 10.1016/0012-821X(94)00237-S.

Dobretsov N.L., 1993. Geology and Tectonics of Gorny Altai. Guide-Book for Post-Symposium Excursion of the 4th International Symposium of the IGCP Project 283 "Geodynamic Evolution of the Paleoasian Ocean". Novosibirsk, $122 \mathrm{p}$.

Dobretsov N.L., 1995. Problems of the relationship of tectonics and metamorphism. Petrologiya (Petrology) 3 (1), 4-23 (in Russian) [Добрецов Н.Л. Проблемы соотношения тектоники и метаморфизма // Петрология. 1995. T. 3. № 1. C. 4-23].

Dobretsov N.L., Kirdyashkin A.G., Kirdyashkin A.A., 2001. Deep-Level Geodynamics. Siberian Branch of RAS Publishing House, Geo Branch, Novosibirsk, 408 p. (in Russian) [Добрецов Н.Л., Кирдяшкин А.Г., Кирдяшкин А.А. Глубинная геодинамика. Новосибирск: Изд-во СО РАН, филиал «ГЕО», 2001. 408 с.].

Egorova V.V., Volkova N.I., Shelepaev R.A., Izokh A.E., 2006. The lithosphere beneath Sangilen Plateau, Siberia: evidence from peridotite, pyroxenite and gabbro xenoliths from alkaline basalts. Mineralogy and Petrology 88 (3-4), 419-441. https://doi.org/10.1007/s00710-006-0121-0.

Khain V.E., Lobkovsky L.I., 1990. On the features of the formation of collision orogens. Geotektonika (Geotectonics) (6), 20-31. (in Russian) [Хаин В.Е., Лобковский Л.И. Об особенностях формирования коллизионных орогенов // Геотектоника. 1990. № 6. С. 20-31].

Khain V.E., Tychkov S.A., Vladimirov A.G., 1996. Collision orogeny: a model for the detachment of a subducted oceanic lithosphere plate as a result of continental collision. Geologiya i Geofizika (Russian Geology and Geophysics) 37 (1), 5-16 [Хаин В.E., Тычков С.А., Владимиров А.Г. Коллизионный орогенез: модель отрыва субдуцированной пластины океанической литосферы при континентальной коллизии // Геология и геофизика. 1996. Т. 37. № 1. C. 5-16].

Khanchuk A.I., Grebennikov A.V., Ivanov V.V., 2019. Albian-Cenomanian marginal continental orogenic belt and the magmatic province of Pacific Asia. Russian Journal of Pacific Geology 38 (3), 4-37 (in Russian) [Ханчук А.И., Гребенников А.В., Иванов В.В. Альб-Сеноманские окраинно-континентальный орогенный пояс и магматическая провинция Тихоокеанской Азии // Тихоокеанская геология. 2019. Т. 38. № 3. С. 4-37].

Kirdyashkin A.A., Kirdyashkin A.G., Surkov N.V., 2019. Features of melting in the thermichemical plume conduit and heat and mass transfer during crystallization differentiation of basaltic melt in a mushroom-shaped plume head. Geodynamics \& Tectonophysics 10 (1), 1-19 (in Russian) [Кирдяшкин А.А., Кирдяшкин А.Г., Сурков Н.В. Особенности плавления в канале термохимического плюма и тепломассообмен при кристаллизационной дифференциации базальтового расплава в грибообразной голове плюма // Геодинамика и тектонофизика. 2019 T. 10. № 1. C. 1-19]. https://doi.org/10.5800/GT-2019-10-1-0401.

Kirdyashkin A.G., Kirdyashkin A.A., Distanov V.E., Gladkov I.N., 2019. Experimental and theoretical modeling of diamondiferous plumes. Geodynamics \& Tectonophysics 10 (2), 247-263 (in Russian) [Кирдяшкин А.Г., Кирдяшкин А.А., Дистанов В.Э., Гладков И.Н. Экспериментальное и теоретическое моделирование алмазоносных плюмов // Геодинамика и тектонофизика. 2019. T. 10. № 2. C. 247-263]. https://doi.org/10.5800/GT-2019-10-2-0413. 
Kuskov O.L., Kronrod V.A., Prokofyev A.A., Pavlenkova N.I., 2014. Thermochemical structure of the lithospheric mantle underneath the Siberian craton inferred from long-range seismic profiles. Tectonophysics 615-616, 154-166. https://doi.org/10.1016/j.tecto.2014.01.006.

Kuznetsov Yu.A., Izokh E.P., 1969. Geological evidence of intratelluric fluxes of heat and mass as agents of metamorphism and magma generation. In: Yu.A. Kuznetsov (Ed.), Problems of petrology and metallogeny, Vol. 1. Nauka, Moscow, p. 7-20 (in Russian) [Кузнецов Ю.А., Изох Э.П. Геологические свидетельства интрателлурических потоков тепла и вещества как агентов метаморфизма и магмообразования // Проблемы петрологии и генетической минералогии / Ред. Ю.А. Кузнецов. М.: Наука, 1969. Т. 1. С. 7-20].

Lobkovsky L.I., Nikishin A.I., Khain V.I., 2004. Modern Problems of Geotectonics and Geodynamics. Nauchny Mir, Moscow, 612 p. (in Russian) [Лобковский Л.И., Никишин А.И., Хаин В.И. Современные проблемы геотектоники и геодинамики. М.: Научный мир, 2004. 612 с.].

Martynov Yu.A., Golozubov V.V., Khanchuk A.I., 2016. Mantle diapirism at convergent boundaries (Sea of Japan). Russian Geology and Geophysics 57 (5), 745-755. https://doi.org/10.1016/j.rgg.2015.09.016.

Morgan J.P., Reston T.J., Ranero C.R., 2004. Contemporaneous mass extinctions, continental flood basalts, and 'impact signals': are mantle plume-induced lithospheric gas explosions the causal link? Earth and Planetary Science Letters 217 (3-4), 263-284. https://doi.org/10.1016/S0012-821X(03)00602-2.

Morgan W.J., 1971. Convection plumes in the lower mantle. Nature 230 (5288), 42-43. https://doi.org/10.1038/ $230042 \mathrm{a} 0$.

Murzintsev N.G., Annikova I.Yu., Travin A.V., Vladimirov A.G., Dyachkov B.A., Maslov V.I., Oitseva T.A., Gavryushkina O.A., 2019. Thermochronology and mathematical modeling of the formation dynamics of rare-metal-granite deposits of the Altai collision system. Geodynamics \& Tectonophysics 10 (2) 375-404 (in Russian) [Мурзинцев Н.Г., Анникова И.Ю., Травин А.В., Владимиров А.Г., Дьячков Б.А., Маслов В.И., Ойцева Т.А., Гаврюшкина О.А. Термохронология и математическое моделирование динамики формирования редкометалльно-гранитных месторождений Алтайской коллизионной системы // Геодинамика и тектонофизика. 2019. Т. 10. № 2. С. 375-404]. https://doi.org/10.5800/GT-2019-10-2-0419.

Norton I.O., 2000. Global hotspot reference frames and plate motion. In: M.A. Richards, R.G. Gordon, R.D. Van Der Hilst (Eds.), The history and dynamics of global plate motions. AGU Geophysical Monograph Series, vol. 121, p. 339-357. https://doi.org/10.1029/GM121p0339.

O'Reilly S.Y., Griffin W.L., 2013. Moho vs crust - mantle boundary: evolution of an idea. Tectonophysics 609, 535-546. https://doi.org/10.1016/j.tecto.2012.12.031.

Osipova T.A., Kallistov G.A., Zaitceva M.V., 2019. Zircon in high-Mg diorite of the Chelyabinsk massif (South Urals): morphology, geochemical signature, and petrogenesis implications. Geodynamics \& Tectonophysics 10 (2), 289-308 (in Russian) [Осипова T.A., Каллистов Г.А., Зайцева М.В. Циркон из высокомагнезиального диорита Челябинского массива (Южный Урал): морфология, геохимические особенности, петрогенетические аспекты // Геодинамика и тектонофизика. 2019. T. 10. № 2. C. 289-308]. https://doi.org/10.5800/GT-2019-10-2-0415.

Polyansky O.P., Kargopolov S.A., Izokh A.E., Semenov A.N., Babichev A.V., Vasilevsky A.N., 2019. The role of magmatic heat sources in the formation of regional and contact metamorphic areas in West Sangilen (Tuva, Russia). Geodynamics \& Tectonophysics 10 (2), 309-323 (in Russian) [Полянский О.П., Каргополов С.А., Изох А.Э., Семенов А.Н., Бабичев A.B., Василевский A.H. Роль магматических источников тепла при формировании регионального и контактовых метаморфических ареалов Западного Сангилена (Тува) // Геодинамика и тектонофизика. 2019. T. 10. № 2. C. 309-323]. https://doi.org/10.5800/GT-2019-10-2-0416.

Puchkov V.N., 2007. Plume- and plate tectonics interrelations in the perspective of the development of the global geodynamic theory. In: Geodynamics, magmatism, metamorphism and mineralization. IGG Ural Branch RAS, Ekaterinburg, p. 23-51 (in Russian) [Пучков В.Н. Взаимоотношения плюм- и плейт-тектоники в перспективе развития глобальной геодинамической теории // Геодинамика, магматизм, метаморфизм и рудообразование. Екатеринбург: ИГХ УрО РАН, 2007. С. 23-51].

Ricard Y., 2007. Physics of mantle convection. In: D. Bercovici (Ed.), Mantle dynamics. Treatise on Geophysics, vol. 7, p. 437-505.

Rudnev S.N., 2010. Early Paleozoic Granitoid Magmatism of the Altai-Sayan Folded Region and Lake Zone of Western Mongolia. Author's brief thesis (Doctor of Geology and Mineralogy). Novosibirsk, 32 p. (in Russian) [Руднев C.H. Раннепалеозойский гранитоидный магматизм Алтае-Саянской складчатой области и Озерной зоны Западной Монголии: Автореф. дис. ... докт. геол.-мин. наук. Новосибирск, 2010. 32 с.].

Schubert G., Masters G., Olson P., Tackley P., 2004. Superplumes or plume clusters? Physics of the Earth and Planetary Interiors 146 (1-2), 147-162. https://doi.org/10.1016/j.pepi.2003.09.025.

Shelepaev R.A., Egorova V.V., Izokh A.E., Seltmann R., 2018. Collisional mafic magmatism of the fold-thrust belts framing southern Siberia (Western Sangilen, southeastern Tuva). Russian Geology and Geophysics 59 (5), 525-540. https:// doi.org/10.1016/j.rgg.2018.04.006.

Shokal'skii S.P., Babin G.A., Vladimirov A.G., Borisov S.M., Gusev N.I., Tokarev V.N., Zybin V.A., Dubskii V.S., Murzin O.V., Krivchikov V.A., Kruk N.N., Rudnev S.N., Fedoseev G.S., Titov A.V., Sergeev V.P., Likhachev N.N., Mamlin A.N., Kotel'nikov E.I., Kuznetsov S.A., Zeifert L.L., Yashin V.D., Noskov Yu.S., Uvarov A.N., Fedak S.I., Gusev A.I., Vystavnoy S.A., 2000. Correlation of Magmatic and Metamorphic Complexes of the Western Part of the Altai-Sayan Folded Region. 
Siberian Branch of RAS Publishing House, Novosibirsk, 120 p. (in Russian) [Шокальский С.П., Бабин Г.А., Владимиров А.Г., Борисов С.М., Гусев Н.И., Токарев В.Н., Зыбин В.А., Дубский В.С., Мурзин О.В., Кривчиков В.А., Крук Н.Н., Руднев С.Н., Федосеев Г.С., Титов А.В., Сергеев В.П., Лихачев Н.Н., Маллин А.Н., Котельников Е.И., Кузнецов С.А., Зейферт Л.Л., Яшин В.Д., Носков Ю.С., Уваров А.Н., Федак С.И., Гусев А.И., Выставной С.А. Корреляция магматических и метаморфических комплексов западной части Алтае-Саянской складчатой области. Новосибирск: Изд-во СО РАН, Филиал «Гео», 2000. 120 с.].

Thybo H., Artemieva I.M., 2013. Moho and magmatic underplating in continental lithosphere. Tectonophysics 609, 605-619. https://doi.org/10.1016/j.tecto.2013.05.032.

Travin A.V., 2016. Thermochronology of Early Paleozoic collisional and subduction-collisional structures of Central Asia. Russian Geology and Geophysics 57 (3), 434-450. https://doi.org/10.1016/j.rgg.2016.03.006.

Trubitsyn V.P., 2012. Rheology of the mantle and tectonics of the oceanic lithospheric plates. Izvestiya, Physics of the Solid Earth 48 (6), 467-485. https://doi.org/10.1134/S1069351312060079.

Trubitsyn V.P., Evseev M.N., 2014. Mantle plumes at the boundary of the upper and lower mantle. Doklady Earth Sciences 459 (1), 1397-1399. https://doi.org/10.1134/S1028334X14110099.

Trubitsyn V.P., Evseev M.N., 2018. Plume mode of thermal convection in the Earth's mantle. Izvestiya, Physics of the Solid Earth 54 (6), 838-848. https://doi.org/10.1134/S1069351318060125.

Trubitsyn V.P., Evseev M.N., Trubitsyn A.P., 2015. Influence of continents and lithospheric plates on the shape of $\mathrm{D}^{\prime \prime}$ layer and the spatial distribution of mantle plumes. Russian Journal of Earth Sciences 15 (3), ES3001. https:// doi.org/10.2205/2015ES000552.

Turkina O.M., 2002. Petrology of the Precambrian Tonalite-Trondhjemite Complexes of the Southwestern Margin of the Siberian Craton. Author's brief thesis (Doctor of Geology and Mineralogy). Novosibirsk, 38 p. (in Russian) [Туркина O.M. Петрология докембрийских тоналит-трондьемитовых комплексов юго-западной окраины Сибирского кратона: Автореф. дис. ... докт. геол.-мин. наук. Новосибирск, 2002. 38 с.].

Tychkov S.A., Vladimirov A.G., 1997. Model of break-off of the subducted oceanic lithosphere in the Indo-Eurasian collision zone. Doklady Earth Sciences 354 (4), 515-518.

Udoratina O.V., Coble M.A., Shuyskiy A.S., Kapitanova V.A., 2019. Mafic inclusions (Sobsky complex, Polar Ural): U-Pb (SIMS) data. Geodynamics \& Tectonophysics 10 (2) 265-288 (in Russian) [Удоратина О.В., Кобл М.А., Шуйский A.C., Капитанова B.A. Мафические включения (собский комплекс, Полярный Урал): U-Pb (SIMS) данные // Геодинамика и тектонофизика. 2019. Т. 10. № 2. C. 265-288]. https://doi.org/10.5800/GT-2019-10-2-0414.

van Keken P.E., 1997. Evolution of starting mantle plumes: a comparison between numerical and laboratory models. Earth and Planetary Science Letters 148 (1-2), 1-11. https://doi.org/10.1016/S0012-821X(97)00042-3.

van Keken P.E., Ballentine C.J., 1999. Dynamical models of mantle volatile evolution and the role of phase transitions and temperature-dependent rheology. Journal of Geophysical Research: Solid Earth 104 (B4), 7137-7151. https:// doi.org/10.1029/1999JB900003.

Vladimirov A.G., Izokh A.E., Polyakov G.V., Babin G.A., Mekhonoshin A.S., Kruk N.N., Khlestov V.V., Khromykh S.V., Travin A.V., Yudin D.S., Shelepayev R.A., Karmysheva I.V., Mikheev E.I., 2013. Gabbro-granite intrusive series and their indicator importance for geodynamic reconstructions. Petrology 21 (2), 158-180. https://doi.org/10.1134/ S0869591113020070.

Vladimirov A.G., Kruk N.N., Khromykh S.V., Polyansky O.P., Chervov V.V., Vladimirov V.G., Travin A.V., Babin G.A., Kuibida M.L., Khomyakov V.D., 2008. Permian magmatism and lithospheric deformation in the Altai caused by crustal and mantle thermal processes. Russian Geology and Geophysics 49 (7), 468-479. https://doi.org/10.1016/ j.rgg.2008.06.006.

Vladimirov A.G., Mekhonoshin A.S., Khromykh S.V., Mikheev E.I., Travin A.V., Volkova N.I., Kolotilina T.B., Davydenko Yu.A., Borodina E.V., Khlestov V.V., 2017. Mechanisms of mantle crust interaction at deep levels of collision orogens (case of the Olkhon region, West Pribaikalie). Geodynamics \& Tectonophysics 8 (2), 223-268 (in Russian) [Владимиров А.Г., Мехоношин А.С., Хромых С.В., Колотилина Т.Б., Волкова Н.И., Травин А.В., Михеев Е.И., Давыденко Ю.А., Бородина E.B., Хлестов В.В. Динамика мантийно-корового взаимодействия на глубинных уровнях коллизионных орогенов (на примере Ольхонского региона, Западное Прибайкалье) // Геодинамика и тектонофизика. 2017. T. 8. № 2. C. 223-268]. https://doi.org/10.5800/GT-2017-8-2-0240.

Vladimirov A.G., Travin A.V., Phan Luu Anh, Murzintsev N.G., Annikova I.Yu., Mikheev E.I., Nguyen Anh Duong, Tran Thi Man, Tran Thi Lan, 2019. Thermochronology of granitoid batholiths and their transformation into metamorphic core complexes (example of Song-Chai massif, Northern Vietnam). Geodynamics \& Tectonophysics 10 (2), 347-373 (in Russian) [Владимиров А.Г., Травин А.В., Фан Лыу Ань, Мурзинцев Н.Г., Анникова И.Ю., Михеев Е.И., Нгуен Ань Зыонг, Чан Тхи Ман, Чан Тхи Лан. Термохронология гранитоидных батолитов и их трансформация в комплексы метаморфических ядер (на примере массива Шонгчай, Северный Вьетнам) // Геодинамика и тектонофизика. 2019. T. 10. № 2. C. 347-373]. https://doi.org/10.5800/GT-2019-10-2-0418.

Vladimirov A.G., Vladimirov V.G., Polyansky O.P., 2017. Mingling processes in the Earth's crust: geological observations and mathematical simulation. Geodynamics \& Tectonophysics 8 (2), 217-222 (in Russian) [Владимиров А.Г., Владимиров В.Г., Полянский О.П. Минглинг-процессы в земной коре: геологические наблюдения и математическое моделирование // Геодинамика и тектонофизика. 2017. Т. 8. № 2. С. 217-222]. https://doi.org/ 10.5800/GT-2017-8-2-0239. 
Vladimirov V.G., Yakovlev V.A., Karmysheva I.V., 2019. Mechanisms of magmatic mingling in composite dykes: models of dispersion and shear dilatation. Geodynamics \& Tectonophysics 10 (2), 325-345 (in Russian) [Владимиров В.Г., Яковлев В.А., Кармышева И.В. Механизмы магматического минглинга в композитных дайках: модели диспергирования и сдвиговой дилатации // Геодинамика и тектонофизика. 2019. Т. 10. № 2. С. 325-345]. https://doi.org/10.5800/GT-2019-10-2-0417.

Yoshida M., Santosh M., 2011. Supercontinents, mantle dynamics and plate tectonics: a perspective based on conceptual vs. numerical models. Earth-Science Reviews 105 (1-2), 1-24. https://doi.org/10.1016/j.earscirev.2010.12.002.

Zhong S., 2006. Constraints on thermochemical convection of the mantle from plume heat flux, plume excess temperature, and upper mantle temperature. Journal of Geophysical Research: Solid Earth 111 (B4), B04409. https:// doi.org/10.1029/2005JB003972.

Zhong S., Zuber M.T., Moresi L., Gurnis M., 2000. Role of temperature-dependent viscosity and surface plates in spherical shell models of mantle convection. Journal of Geophysical Research: Solid Earth 105 (B5), 11063-11082. https://doi.org/10.1029/2000JB900003.

Александр Геннадьевич Владимиров

докт. геол.-мин. наук, профессор

Институт геологии и минералогии им. В.С. Соболева СО РАН

630090, Новосибирск, пр. Академика Коптюга, 3, Россия

Новосибирский национальный исследовательский

государственный университет

630090, Новосибирск, ул. Пирогова, 2, Россия

Томский государственный университет

634050, Томск, пр. Ленина, 50, Россия

凶e-mail: vladimir@igm.nsc.ru

(iD) https://orcid.org/0000-0001-7884-2601

\section{Николай Николаевич Крук}

докт. геол.-мин. наук, директор института

Институт геологии и минералогии им. В.С. Соболева СО РАН

630090, Новосибирск, пр. Академика Коптюга, 3, Россия

e-mail: kruk@igm.nsc.ru

\section{Олег Петрович Полянский}

докт. геол.-мин. наук, зав. лабораторией

Институт геологии и минералогии им. В.С. Соболева СО РАН 630090, Новосибирск, просп. Академика Коптюга, 3, Россия

Новосибирский национальный исследовательский государственный университет

630090, Новосибирск, ул. Пирогова, 2, Россия

e-mail: pol@igm.nsc.ru

(iD) https://orcid.org/0000-0003-2760-0754

\section{Aleksander G. Vladimirov}

Doctor of Geology and Mineralogy, Professor

V.S. Sobolev Institute of Geology and Mineralogy, Siberian Branch of RAS 3 Academician Koptyug ave., Novosibirsk 630090, Russia

Novosibirsk State University

2 Pirogov street, Novosibirsk 630090, Russia

Tomsk State University

50 Lenin ave., Tomsk 634050, Russia

\section{Nikolai N. Kruk}

Doctor of Geology and Mineralogy, Director of the Institute

V.S. Sobolev Institute of Geology and Mineralogy, Siberian Branch of RAS 3 Academician Koptyug ave., Novosibirsk 630090, Russia

\section{Oleg P. Polyansky}

Doctor of Geology and Mineralogy, Head of Laboratory

V.S. Sobolev Institute of Geology and Mineralogy, Siberian Branch of RAS 3 Academician Koptyug ave, Novosibirsk 630090, Russia

Novosibirsk State University

2 Pirogov street, Novosibirsk 630090, Russia 
A.G. Vladimirov et al.: Heat and mass transfer in the upper mantle and the deep crust...

\section{Алексей Валентинович Травин}

докт. геол.-мин. наук

Институт геологии и минералогии им. В.С. Соболева СО РАН

630090, Новосибирск, пр. Академика Коптюга, 3, Россия

Новосибирский национальный исследовательский

государственный университет

630090, Новосибирск, ул. Пирогова, 2, Россия

Томский государственный университет

634050, Томск, пр. Ленина, 50, Россия

e-mail: travin@igm.nsc.ru

(iD) https://orcid.org/0000-0002-5640-4560

\section{Aleksei V. Travin}

Doctor of Geology and Mineralogy

V.S. Sobolev Institute of Geology and Mineralogy, Siberian Branch of RAS 3 Academician Koptyug ave., Novosibirsk 630090, Russia

Novosibirsk State University

2 Pirogov street, Novosibirsk 630090, Russia

Tomsk State University

50 Lenin ave., Tomsk 634050, Russia 